\title{
PSICANÁLISE E NEUROCIÊNCIAS: UM MAPA DOS DEBATES ${ }^{1}$
}

\author{
Marcia Moraes Davidovich \\ Monah Winograd
}

\begin{abstract}
RESUMO. Este artigo pretende apresentar um mapa panorâmico dos debates em torno da relação e da possível articulação entre a psicanálise e as neurociências. No campo psicanalítico são identificados três grupos principais, definidos a partir de seus pressupostos: (1) hibridação, (2) isolamento e (3) interlocução. O primeiro grupo entende ser necessária a construção de um campo híbrido, já que as neurociências poderiam fornecer à psicanálise fundamentos e instrumentos metodológicos e conceituais mais sólidos sobre o funcionamento psíquico. Esta proposta vem sendo desenvolvida com a fundação da neuropsicanálise. Já o segundo grupo, marcado fortemente pelo discurso lacaniano, é refratário a qualquer forma de articulação, por considerá-las todas epistemologicamente inviáveis, resultando necessariamente em uma submissão da psicanálise aos ditames cientificistas atuais. Por fim, o terceiro grupo entende ser a interlocução, sem a hierarquização dos modelos em jogo, fonte fértil para a formulação de novas hipóteses teóricas e para a revisão do edifício conceitual da psicanálise.
\end{abstract}

Palavras-chave: Psicanálise; neurociências; neuropsicanálise.

\section{PSYCHOANALYSIS AND NEUROSCIENCES: A MAP OF THE DEBATES}

\begin{abstract}
This article will present an overview of the debate about the connections between psychoanalysis and neuroscience. In the psychoanalytic camp, the three main groups are identified as: (1) hybridisation, (2) isolation and (3) interlocution. The first group understands the need for creating a hybrid field, as neurosciences can provide psychoanalysis with underpinnings, methodological techniques and firmer concepts of mental function. This idea is developing as the foundation of Neuropsychoanalysis. The second group, marked strongly by the lacanian discourse, rejects any linkage, thinking them epistemologically incompatible, and predicting an inevitable subjugation of psychoanalysis to scientific dictums. Finally the third group understands interlocution, without hierarchification of the models in play, as a fertile ground for the formulation of new hypotheses and the renovation of the conceptual edifice of psychoanalysis.
\end{abstract}

Key words: Psychoanalysis; neurosciences; neuropsychoanalysis.

\section{PSICOANÁLISIS Y NEUROCIENCIAS: UN MAPA DE LOS DEBATES}

RESUMEN. Este artículo pretende presentar un mapa panorámico de los debates sobre la relación y la posible articulación entre Psicoanálisis e Neurociencias. En el campo psicoanalítico, son identificados tres grupos principales, definidos a partir de sus presuposiciones: (1) hibridismo, (2) aislamiento e (3) interlocución. El primer grupo entiende como necesaria la construcción de un campo híbrido, ya que las Neurociencias podrían suministrar a la Psicoanálisis fundamentos e instrumentos metodológicos y conceptuales más sólidos sobre el funcionamiento psíquico. A su vez el segundo grupo, marcado fuertemente por el discurso lacaniano, es refractario a cualquier forma de articulación por considerarla epistemológicamente inviable y resultando necesariamente en una sumisión de la psicoanálisis al dictamen cientificista actual. Por último, el tercer grupo entiende que la articulación sin la jerarquización de los modelos en juego, es fuente fértil para la formulación de nuevas hipótesis teóricas y para la revisión del edificio conceptual de la psicoanálisis.

Palabras-clave: Psicoanálisis; neurociencias; neuropsicoanálisis.

Este trabalho é fruto das atividades do grupo de pesquisa Matéria Pensante com o apoio do CNPq (processo 401750/2007-8).

Mestre em Psicologia Clínica pela Pontifícia Universidade Católica do Rio. Doutoranda em Psicologia Clínica na PUC-Rio. Membro provisório da Sociedade Brasileira de Psicanálise do Rio de Janeiro.

\# Psicanalista. Doutora em Teoria Psicanalítica pela Universidade Federal do Rio de Janeiro. Professora assistente do departamento de Psicologia da PUC-Rio. Coordenadora do programa de pós-graduação em Psicologia Clínica da PUC-Rio. 
Há pouco tempo teve início um movimento que busca integrar o conhecimento produzido pelas diferentes áreas das neurociências com aquele específico à Psicanálise. O propósito deste artigo é apresentar os diversos grupos que se formaram no campo psicanalítico em torno das (im)possibilidades de interlocução entre os dois campos e destacar brevemente o que pode ser formulado quer na esfera básica da produção de conhecimento quer na área clínica, relativamente à compreensão dos processos envolvidos na intervenção psicoterapêutica. Pode-se notar serem basicamente três os posicionamentos principais $^{2}$ que podem ser encontrados em função dos pressupostos implícitos de cada autor - guardadas, evidentemente, suas diferenças específicas. Ao primeiro grupo, demos a denominação de grupo da hibridação, por propor uma composição entre a psicanálise e as neurociências em um novo campo, a saber, a Neuropsicanálise. O segundo foi chamado de grupo do isolamento, por se entender que não há condições epistemológicas para nenhum tipo de diálogo - o que resulta na impossibilidade tanto de uma integração quanto de qualquer outro tipo de contato entre os saberes em jogo. Finalmente, o terceiro grupo foi caracterizado como grupo da interlocução, já que os autores que o compõem acreditam que não se trata nem da produção de um campo híbrido nem da impossibilidade de dialogar. Trata-se, ao contrário, da fertilidade de uma pesquisa interdisciplinar na qual as especificidades epistemológicas e metodológicas de cada campo são mantidas. Importa sublinhar que tais agrupamentos e suas denominações têm a função única de facilitar a distinção dos discursos envolvidos no debate a partir das premissas que se podem identificar em cada um deles. Não se pretende com isso negligenciar ou obnubilar as diferenças entres as formulações e propostas dos diversos autores.

\section{A NEUROPSICANÁLISE: ELOGIO AO MÉTODO EXPERIMENTAL}

O primeiro grupo, que chamamos de hibridação, especifica-se pelo entendimento de que a psicanálise não teria evoluído "cientificamente" por não ter desenvolvido métodos empíricos objetivos para testar suas hipóteses, o que fez com que se tornasse obsoleta e devesse se revigorar. Para atingir esse objetivo, a Psicanálise deveria importar o modelo de ciência

2 Esta divisão em três grupos foi inspirada no artigo de Benilton Bezerra Jr. (2006) intitulado "O impacto das biotecnologias: um ponto de vista". adotado nas ciências físicas e naturais, experimentalizando-se para se tornar, enfim, científica. As neurociências poderiam fornecer à psicanálise fundamentos empíricos e conceituais mais sólidos sobre o funcionamento psíquico, entre os quais se destacariam os oriundos das novas tecnologias de neuroimagem, além dos achados da Neuropsicologia Cognitiva.

O pontapé inicial para este movimento foi dado por Eric Kandel (1999), ao expressar o que acredita ter sido a grande falha da Psicanálise em seu desenvolvimento:

\begin{abstract}
Muitas áreas médicas progrediram ao incorporar metodologias e conceitos de outras disciplinas, sendo que a Psicanálise falhou nesse aspecto, já que a Psicanálise ainda não se reconhece como um ramo da biologia. Ela não incorporou para a visão psicanalítica da mente os ricos conhecimentos sobre a biologia do cérebro e seu controle do comportamento que foi identificado nos últimos 50 anos (Kandel, 1999, p. 507).
\end{abstract}

Ainda que Kandel (1999) reconheça que a Psicanálise revolucionou nossa compreensão sobre a vida mental, oferecendo insights notáveis sobre processos mentais inconscientes e, principalmente, a irracionalidade das motivações humanas, ele entende que o mesmo vigor não pôde ser observado nos anos posteriores, pois, embora o pensamento psicanalítico continue progredindo, tem havido poucos insights brilhantes, com exceção das teorias sobre o desenvolvimento infantil ${ }^{3}$. Kandel acredita que, conquanto a Psicanálise ainda represente a visão de mente mais coerente e cientificamente satisfatória dentre as que existem, ela entrou no século XXI em declínio por não ter desenvolvido métodos objetivos para testar suas ideias — o que só pode acontecer através de seu fortalecimento a partir de sua aproximação teórica e, sobretudo, metodológica, com a biologia em geral e com as neurociências cognitivas em particular.

Relativamente ao aspecto metodológico, Kandel marca sua posição ao afirmar que "a Psicanálise foi sempre melhor em gerar ideias do que testá-las" (p. 506). Embora reconheça que a privacidade da comunicação é central para a confiança básica engendrada na situação psicanalítica, considera que

Aqui Kandel se refere ao autor L. Isenstadt que abordou o tema do desenvolvimento infantil no artigo intitulado The neurobiology of childhood emotion: anxiety, publicado em 1998, no Am Psychoanalyst; 32(3). 
isto gera um impasse, pois só fornece as considerações subjetivas do analista a respeito do que ele acredita ter ocorrido. Para este pesquisador, uma das grandes limitações dos estudos psicanalíticos dos processos psíquicos foi justamente a inexistência de um método capaz de observação direta desses processos. Assim, uma contribuição-chave que a Biologia pode atualmente fornecer - através da neuroimagem e do estudo de pacientes com lesões em diferentes componentes da memória - é mudar a base do estudo dos processos mentais da inferência indireta para a observação direta. Kandel (1999) entende que uma aproximação entre a Psicanálise e a Neurociência Cognitiva geraria ainda um avanço conceitual para a primeira, já que a última poderia prover, além da metodologia, também um novo instrumental teórico para seu crescimento futuro. Como sugerem Olds e Cooper (1997), a Neurociência Cognitiva poderia ajudar a reescrever a metapsicologia em base científica.

O resultado deste movimento foi o surgimento da Neuropsicanálise. Em 1999 foi publicado o $1^{\circ}$ número da revista Neuro-psychoanalysis, de cujo corpo editorial fazem parte neurocientistas de renome, como o prêmio Nobel Eric Kandel, António Damásio e Oliver Sacks, e psicanalistas célebres, como Charles Brenner, André Green, Otto Kernberg e Daniel Widlöcher. Pouco tempo depois, em julho de 2000, foi realizado em Londres o $1^{\circ}$ Congresso Internacional de Neuropsicanálise - ocasião em que foi fundada a Sociedade Internacional de Neuropsicanálise pelo psicanalista e neurocientista Mark Solms e por sua esposa, Karen Kaplan-Solms, fonoaudióloga, neuropsicóloga e também psicanalista. Desde então, a cada ano um novo congresso internacional vem sendo realizado, congregando cada vez mais estudiosos de todo o mundo e consolidando as posições teóricas e metodológicas dos que entendem ser necessário estabelecer um campo híbrido entre a Psicanálise e as neurociências.

Um dos caminhos percorridos por esses pesquisadores no intuito de sustentar epistemológica e metodologicamente o empreendimento neuropsicanalítico foi a retomada de textos freudianos históricos e precoces (anteriores a 1900 e relativos ao que se convencionou chamar de período prépsicanalítico ou neurológico de sua produção) para mostrar a compatibilidade que eles afirmam existir entre os pressupostos de Freud - em termos da correlação entre os processos psíquicos e os neurológicos - e aqueles observados na pesquisa neuropsicanalítica. Eles alegam que a insuficiência do conhecimento das ciências do cérebro da época foi o motivo principal pelo qual Freud se viu impedido de realizar o que a Neuropsicanálise atualmente pretende.

Kaplan-Solms e Solms (2005) salientam que o objetivo da pesquisa neuropsicanalítica é modesto e, ao mesmo tempo, de longo alcance. É modesto no sentido de introduzir a combinação de dois métodos anteriormente separados, e de longo alcance, no sentido daquilo que se pode adquirir a partir da aplicação desse novo método. Eles acreditam que o método neuropsicanalítico possa viabilizar o caminho para uma integração - em uma base empírica - da Psicanálise e das neurociências. Em suma, eles definem a sua "proposta metodológica" da seguinte forma: "a técnica de associação-livre deve ser introduzida no método neuropsicológico de Luria" (Kaplan-Solms \& Solms, 2005, p. 88), que se caracteriza por dois estágios: (1) qualificação dos sintomas e (2) análise da síndrome.

Apesar de reconhecer que a psicanálise "é o melhor método disponível quando se chega àqueles aspectos mais profundos da vida mental que a Neuropsicologia não estudou" (Kaplan-Solms \& Solms, 2005, p. 89), os autores afirmam que, ironicamente, devemos o desenvolvimento de um procedimento clínico, ou seja, o método psicanalítico, ao fato de Freud ter abandonado métodos científicos de investigação quando se deu conta de que eles eram incapazes de acomodar a natureza dinâmica $e$ "virtual" dos processos mentais; e acrescentam que agora chegou a hora de reintroduzirmos os frutos dos trabalhos de Freud no campo neurocientífico, fora do qual eles originalmente cresceram. Ao fazê-lo, os pesquisadores acreditam estar aptos "a reunir a psicanálise com a neurociência, numa base clínica sólida (...)" (Kaplan-Solms \& Solms, 2005, p. 89).

Tendo em vista os pressupostos a partir dos quais a Neuropsicanálise opera - quais sejam, que as neurociências poderiam fornecer à psicanálise fundamentos empíricos e conceituais mais sólidos sobre o funcionamento psíquico, o que resulta na tentativa de se formar um campo híbrido - pensamos ser contraditória a posição de Mark Solms a respeito do próprio método de pesquisa quando afirma que "através desse método, as funções psicológicas ainda são compreendidas em seus próprios termos psicológicos; sua estrutura essencial, dinâmica, é respeitada e resguardada; elas não são reduzidas à anatomia e à fisiologia (...)" (Kaplan-Solms \& Solms, 2005, p. 64). O que, na verdade, observamos através da análise dos casos clínicos atendidos por esses pesquisadores (Kaplan-Solms \& Solms, 2004, 2005) é uma fusão da "compreensão" psicanalítica com a "descrição" neuropsicológica, o que indicaria, a nosso 
ver, uma tentativa de tornar a psicanálise "científica" e "mais aceita" por outras áreas do saber, que, por sua vez, poderiam conferir credibilidade às hipóteses psicanalíticas.

Considerando-se o que está implícito neste grupo, ou seja, uma hierarquização de modelos epistemológicos em que é conferido às neurociências um lugar de privilégio em relação à psicanálise, exacerba-se o risco de se realizar nessas pesquisas uma redução explicativa, e não apenas a necessária redução metodológica. Andrieu (2000) e Ehrenberg (2004) destacam existir em qualquer campo de investigação uma redução metodológica interna, que é necessária para a constituição de qualquer saber, mas corre o sério risco de deslizar para uma redução explicativa e ideológica, ou seja, para uma explicação generalizada a partir de resultados parciais ou válidos somente em um campo inicial. Por exemplo, em um trabalho recente, Solms (2007) identifica a libido conceito metapsicológico que se refere à energia sexual que gera a força mental - com o sistema de recompensa - conceito neurocientífico relacionado com o prazer e comportamentos de adicção, mediado pelo agente químico dopamina. Ele defende que estes conceitos funcionam do mesmo modo, parecendo ignorar que uma possível convergência entre eles não significa uma identidade: aqui seu reducionismo explicativo fica evidente.

Outro pioneiro da Neuropsicanálise é Yusaku Soussumi. De forma aparentemente contraditória aos objetivos epistemológicos da neuropsicanálise, ele defende inicialmente que psicanálise e neurociências sejam ciências com objetos e métodos próprios de investigação, não sendo possível reduzir uma à outra. De acordo com Soussumi (2003), contudo, a Neuropsicanálise, em seu trabalho de investigação em duas vias, deve pretender consolidar cientificamente os conceitos metapsicológicos resultantes de observação acurada em anos de testagem na prática psicanalítica. Às neurociências caberia auxiliar no reconhecimento e na correção dos erros, na afinação e na apuração dos dados imperfeitos e na correlação dos fenômenos psíquicos com os fenômenos neurais concomitantes ao nível dos órgãos, das células e das moléculas. É interessante notar a contradição de Soussumi quando, apesar de afirmar que psicanálise e neurociências são duas ciências que possuem objetos e métodos próprios de investigação, defende que as neurociências poderão consolidar cientificamente conceitos metapsicológicos e apurar dados imperfeitos. Ora, a partir de sua primeira afirmação, poder-se-ia supor que, ao se tratar de metodologias diferentes, seria através do próprio método psicanalítico que se tentaria apurar os dados imperfeitos, e não com outra metodologia, como sugere sua segunda afirmação.

Por sua vez, Kernberg (2006) propõe que o fomento da pesquisa empírica em psicanálise poderia auxiliar no fortalecimento da consistência dos conceitos psicanalíticos, servindo como complemento do método comumente utilizado, qual seja, a formulação de teorias a partir da investigação do material clínico. Seu objetivo, em última análise, é "avançar no conhecimento" e dar garantias ao público a respeito dos efeitos benéficos da psicanálise, além de fortalecer o lugar desta entre as ciências. Segundo sua linha de pensamento, a falta de esforços na comunidade psicanalítica em desenvolver pesquisas sistemáticas sobre sua eficácia acabou por abrir espaços para outras terapias, como as cognitivocomportamentais, as quais realizam pesquisas empíricas constantes. A pesquisa aqui é entendida como observações sistemáticas sob condições controladas que possam levar a novos conhecimentos. A sua crítica principal em relação ao campo psicanalítico refere-se à assunção de que a pesquisa empírica, tal como vem sendo realizada, não chegou a acrescentar algo efetivo à prática psicanalítica e que os avanços significativos na teoria e na técnica psicanalíticas vieram dos trabalhos inspiradores de teóricos e clínicos. Não obstante, ele mesmo admite que Melanie Klein, Edith Jacobson, Winnicott, Bion, André Green e outros foram muito mais importantes em suas contribuições do que qualquer pesquisa empírica em psicanálise. Apesar de reconhecer que a sutileza, a riqueza e a complexidade do processo psicanalítico não podem ser apreendidas em projetos de pesquisa, que têm, necessariamente, uma ação restrita, ele defende que o efeito cumulativo de pesquisas bem dirigidas caminharia nesta direção.

A preocupação com a falta de verificação empírica, que os autores do grupo da hibridação acreditam ameaçar a psicanálise, levou à criação, nos EUA, da Sociedade para o Avanço da Pesquisa Quantitativa (SAQRP), em 1989. O objetivo é fazer com que a psicanálise se atualize constantemente e possa se encaixar e se alinhar mais estreitamente ao conhecimento que a ciência empírica permite. Através dos argumentos do grupo da hibridação, ao defender que a psicanálise deve adotar o método das ciências naturais no sentido de se experimentalizar e, além de importar o seu modelo, importar também os conceitos, observamos a ameaça de distorção que sofre a psicanálise. Se na psicanálise existe um problema de falta de homogeneidade institucional, metodológica ou 
teórica, esse problema deve ser resolvido dentro do próprio campo.

\section{O ISOLAMENTO E A RECUSA AO DIÁLOGO}

O segundo grupo que se pode observar caracteriza-se tipicamente por um discurso inserido na linhagem psicanalítica lacaniana e é refratário a qualquer possibilidade de articulação entre psicanálise e neurociências. Recusa de modo aberto o que considera ser uma diluição da herança psicanalítica e uma submissão epistemológica e ética aos ditames da cultura cientificista e biotecnológica atual ${ }^{4}$. Para este grupo, o enfrentamento das críticas à psicanálise deveria ser feito pela reafirmação de sua singularidade discursiva e prática e pela renovação criativa de seus próprios vocabulários e dispositivos clínicos (Bezerra Jr., 2006). Baseando-se no pensamento de Lacan, os representantes desse grupo discordam de uma articulação entre psicanálise e neurociências, alegando ser uma proposta inviável, já que a psicanálise não poderia ser considerada uma ciência. Deve-se notar que a posição lacaniana apenas reconhece que a psicanálise nasceu da ciência, tendo introduzido nela algo novo, que assume um valor de subversão. $O$ discurso lacaniano orienta-se, em sua maior parte, pelo raciocínio de que "a psicanálise introduziu na ciência aquilo mesmo que, tendo-o inventado e sendo por ele sustentado, a ciência exclui: o sujeito" (Elia, 1999, p. 43). Ou seja, mesmo sendo derivada da ciência, a psicanálise realiza um furo na ciência, por ter como objeto exatamente uma parte que deve ser excluída da ciência para que ela possa funcionar, eliminando a apreensão subjetiva, em detrimento de um dado objetivo mais acurado. Dessa forma, o sujeito da ciência e o sujeito da psicanálise seriam o mesmo, portanto o sujeito da psicanálise não pode ser considerado um objeto de estudo da mesma forma que os referentes científicos. Assim, a psicanálise estaria situada em um âmbito bastante resistente à captação conceitual da ciência (Miller, 1987).

Para demonstrar a inviabilidade de uma articulação entre psicanálise e neurociências, a psicanalista Amélia Imbriano (2008), por exemplo, apoiada nas ideias de Lacan, sugere que Freud (1915/2004), ao definir a pulsão (Trieb), cuja fonte é o corpo (organismo), deparou-se com um impasse para o desenvolvimento de sua teoria sobre o psiquismo.

4 Como exemplo, ver Laurent, Eric. Notre politique pour la psychanalyse et celle de l'IPA: trois exemple; e Forbes, J. Complexo de Cinderela, recuperado em 3 de março de 2009 de www.jorgeforbes.com.br. (citado por Bezerra Jr., 2006).
Segundo essa autora, tal impasse só foi superado com as contribuições de Lacan (1964/1979) ao propor, no Seminário XI: Os quatro conceitos fundamentais de psicanálise, uma reformulação do conceito de pulsão, além de outro modo de conceituar o inconsciente, que passa a ser estruturado como linguagem, como efeito de discurso. Imbriano (2008) chama atenção para o fato de que na concepção freudiana de pulsão há uma assimilação da pulsão a algo natural, já que o modelo de ciência utilizado por Freud é o das ciências naturais, revelando um apelo ao modelo fisiológico que lhe serve para pensar a teoria do aparato psíquico, sobretudo no que se refere às aplicações da Física e da Fisiologia, em particular das leis do arco reflexo e da termodinâmica. É por esse motivo que Freud, para definir o conceito de pulsão, faria uma primeira comparação entre o estímulo pulsional - que vem do interior do organismo - e o estímulo do arco reflexo resposta a estímulos externos; porém, diferentemente do estímulo externo, que atua como uma força momentânea e abrupta, a pulsão seria um estímulo contínuo, pois o organismo vivo não cessa seu funcionamento, e o mesmo ocorre com a pulsão, que não cessa de estimular o psiquismo (Freud, 1915/2004). Lacan (1964/1979), por sua vez, propõe outro entendimento para o conceito de pulsão, oferecendo uma nova definição para os seus quatro elementos, e salienta que o modelo da fisiologia que serviu como base para Freud definir a pulsão tornou-se um obstáculo para o desenvolvimento do conceito. Ora, se olharmos atentamente a teoria freudiana da pulsão, poderemos identificar um entendimento distinto daquele que Imbriano defende. Há um trecho onde Freud (1915/2004) deixa claro, em Pulsões e destinos da pulsão, que um dos quatro elementos da pulsão, a fonte - que é orgânica - é de interesse da Biologia, portanto não é da alçada da Psicanálise, donde se conclui que não há, em Freud, uma assimilação da pulsão a algo natural. Não obstante, isto não o impede de admitir o organismo como fonte, já que não é possível conceber a pulsão como algo independente do corpo.

Um ponto que foi questionado sobre a concepção freudiana de pulsão refere-se à satisfação da pulsão. Freud (1920/1976) utiliza o modelo do sistema nervoso, em que há uma tendência a cessar o estímulo externo através do arco-reflexo. Imbriano (2008) recorre a Lacan (1964/1979) para discordar desse ponto, afirmando:

\footnotetext{
A clínica psicanalítica nos mostra a impossibilidade do encontro da pulsão com algo de acordo com os fins da satisfação. Este ‘de acordo' ou 'adequado' não se pode
} 
determinar previamente e por isso sempre se trata de algo em discordância que tem o viés de misterioso e escondido (Imbriano, 2008, p. 182, tradução nossa).

Enquanto Freud estaria regido pelos conhecimentos e pressupostos das ciências naturais, Imbriano (2008) aponta que Lacan se orienta pelo marco epistêmico das ciências conjecturais e encontra nelas a possibilidade de resolver as interrogações e obstáculos que a fisiologia gerou na concepção de Freud. Lacan (1964/1979) apresenta outro modelo: a incidência do significante. Esse é o ponto diferencial entre Freud e Lacan, quando este último traduz o termo pulsão por aventura, vicissitude. Pensar a pulsão como aventura - o impulso que foi identificado por Freud como uma simples tendência à descarga - não é tão simples, pois, para se descarregar, aventura-se (Imbriano, 2008), ou seja, o que é descarregado é um suplemento de energia que foi admitido no aparato psíquico (Lacan, 1964/1979). Imbriano toma como exemplo o elemento Drang - pressão (ou, em espanhol, traduzido pelo termo "impulso") para elucidar as diferentes concepções de Freud e Lacan. Para Freud, Drang - pressão - se refere ao fator motor da pulsão, a quantidade de força ou a medida da exigência de trabalho que ela representa. Deve-se notar que Freud concebe que os estímulos pulsionais se originam no sistema nervoso e exigem um trabalho de eliminação. É este trabalho exigido pela pulsão que vai conduzir às representações psíquicas. Para Lacan (1960/1993), o Drang, ou pressão, já não é uma soma de forças, mas uma excitação produzida pela incidência do significante. No Seminário XI, Lacan (1964/1979), contrariando Freud, argumenta que a constância do impulso impede qualquer assimilação da pulsão a uma função biológica, a qual sempre tem um ritmo. Dito de outro modo, a pulsão não é natural, não se trata de um metabolismo, nem de ritmos biológicos; não é uma função homeostática.

Sonia Alberti (2003), outra autora que parece compartilhar dos pressupostos do grupo do isolamento, afirma que pretende melhor situar as contribuições que a Psicanálise pode dar a questões que advirão com os progressos das pesquisas neurocientíficas, e alerta que seu texto "se inscreve no contexto das conexões da Psicanálise, mesmo sabendo que tanto Freud quanto Lacan partiram de uma tomada de posição frente ao organicismo" (Alberti, 2003, p. 1). O que apreendemos da sua afirmação é que, apesar de falar sobre as possíveis conexões da Psicanálise com a Neurociência, também toma uma posição "frente ao organicismo" porque Freud e Lacan o fizeram. Então cabe a indagação: será que isso significa se opor ao organicismo, no sentido de negar suas contribuições e, assim, isolar-se?

Alberti (2003) faz referência a Lacan (19611962/1981) quando este afirma que o organismo é aspirado pelos efeitos do "isso fala", o que não permite confundir a função da pulsão com a "iminência vital", portanto o modelo mais próximo da pulsão já não é biológico, mas lógico. Ou seja, Lacan prossegue no campo da lógica nesse seminário, negando seu aspecto biológico. Alberti afirma que Lacan "distingue definitivamente a memória orgânica da memória que interessa a nós, analistas" (Alberti, 2003, p. 5). Dito isto, pensamos que quando ela afirma que a memória que interessa a nós analistas é outra, ela deve tomar o cuidado de não ignorar o fato de que a memória que interessa, subjetiva, simbólica, consciente e inconsciente, não pode funcionar caso o seu substrato orgânico esteja comprometido. A memória orgânica, em todos os seus níveis atualmente descritos pelas Neurociências - nível molecular com a LTP, nível de estruturas cerebrais, com a amígdala, o hipocampo, etc., ou no nível dos sistemas, implícito, explícito e seus subsistemas - naturalmente interessa aos psicanalistas, pois é imprescindível para que o psiquismo possa funcionar satisfatoriamente.

O próprio fundador da Psicanálise reconheceu a dependência entre esses dois processos, através da premissa oriunda de Hughlings Jackson da relação entre cérebro e psiquismo de "dependência concomitante". É evidente que cada memória deve ser investigada de forma independente, cada qual com seu próprio método, sem supor que determinado modelo seja superior e que um campo deveria importar o método e a nomenclatura de outro, como pretendem os hibridadores. Tampouco significa supor que nada tenham em comum, de acordo com os isoladores. Assim, isolar a memória subjetiva de seu componente orgânico deve ser feito apenas em termos metodológicos, de forma relativa, pois não se trata de uma diferença absoluta, como parecem supor Lacan e alguns de seus seguidores. Aqui também se observa um reducionismo, mas no sentido inverso das Neurociências, através da exaltação do psíquico em detrimento do orgânico.

Alberti (2003) conclui perguntando: se não há concomitância, se não há relação biunívoca entre o fisiológico e o psicológico, se a "ideia" é para a Psicologia algo muito específico e definível somente na associação com outras ideias, tendo ela própria um caráter elementar, até que ponto a associação de ambas essas línguas, ou seja, a associação de ambos os corpos conceituais e teóricos vela um não saber que Freud (1891) já denunciava, desculpabilizando os 
erros grotescos de tais estudos científicos? Aqui novamente entendemos estar diante de uma posição extremada, para a qual o fato de a especificidade psíquica não poder ser associada à biológica no sentido de uma tradução de conceitos significa que cada especificidade não pode compartilhar seu conhecimento.

\section{O DIÁlOGO NECESSÁRIO E A MANUTENÇÃo DAS ESPECIFICIDADES}

A apresentação e descrição das premissas e de algumas ideias dos dois grupos anteriores revelaram uma polarização entre extremos na qual, de um lado, verifica-se a expectativa de encontrar fundamentos biológicos para proposições psicanalíticas, e de outro, percebe-se a recusa da importância da dimensão biológica na vida psíquica. Entre um extremo e outro, o terceiro grupo se move num campo intermediário, procurando aprofundar a interlocução entre Psicanálise e Neurociência a partir de alguns pressupostos (Bezerra Jr., 2006), entre os quais se destacam: (1) a recusa do fisicalismo e da crença segundo a qual a linguagem da Física é a linguagem de toda ciência, natural ou social e humana; (2) a adoção de uma posição não reducionista e, consequentemente, da recusa crítica ao projeto de tradução exaustiva da experiência subjetiva em termos biológicos e vice-versa; (3) a defesa do pluralismo teórico e metodológico na produção de conhecimento sobre o psiquismo humano, o que supõe o entendimento de que a manutenção das especificidades epistemológicas de cada saber só pode enriquecer o conhecimento, e não limitá-lo; (4) o reconhecimento e exploração da importância da corporeidade na vida psíquica, referida não apenas à problemática das representações conscientes e inconscientes do corpo, mas sobretudo à sua função determinante na constituição psíquica; e (5) a adoção da postura interdisciplinar, segundo a qual a colaboração entre os campos de saber é necessária para a pesquisa dos diversos aspectos do psiquismo humano, sem que seja possível hierarquizá-los.

Nota-se que os pressupostos deste grupo da interlocução se diferenciam daqueles da hibridação, os quais supõem que a Psicanálise é melhor em formular hipóteses do que em testá-las, sendo necessária outra metodologia para lhe dar validade e credibilidade. Por sua vez, para os que não entendem ser a hibridação o melhor caminho, nem rechaçam o diálogo, a Psicanálise não corre o risco de perder o seu lugar, pois o psiquismo não pode ser reduzido ao cerebral. Não obstante, as diferenças epistemológicas não impedem que as áreas possam dialogar, formulando hipóteses novas, cada qual em seu campo próprio, o que não seria possível caso as disciplinas se mantivessem em uma posição de isolamento.

Como exemplo das atividades de interlocução, podem-se citar a clínica psicanalítica com pacientes neurológicos e os desdobramentos teóricos daí resultantes, tais como o problema da cognição na organização psíquica e nos processos psíquicos inconscientes e conscientes. Os distúrbios cognitivos atingem o sujeito em suas sensações de identidade e de existência sustentadas pela memória, pela imagem do corpo, pelo esquema corporal, pela relação com o espaço e a temporalidade, bem como pela continuidade da relação com o outro e pelos processos de reconhecimento de si e do outro. Em outras palavras, a cognição parece ter uma função de apoio interno para o sujeito, permitindo-lhe integrar em seu espaço psíquico as representações de si e do mundo (Winograd, 2005). Tais questões fazem eco ao pensamento de Donald Winnicott, cujas obras representam uma das maiores contribuições à Psicanálise depois de Freud. Winnicott (1960/1988) postula que os distúrbios cognitivos põem o "self" em perigo, uma vez que o sentimento de integridade se apoiaria no desenvolvimento de um "eu integrado", abalado, por exemplo, por distúrbios neurológicos envolvendo a memória ou a noção de tempo do sujeito.

É importante salientar que as abordagens psicanalítica e neuropsicológica são incomparáveis do ponto de vista teórico e epistemológico - o que absolutamente não impede que possam trabalhar lado a lado e em colaboração. Se a Psicanálise é uma prática centrada na transferência e na causalidade psíquica inconsciente, a Neuropsicologia Cognitiva situa-se do lado de uma causalidade científica apoiada no método experimental; porém, em torno do mesmo objeto de investigação (o lugar da cognição na organização psíquica) e da intervenção clínica no acompanhamento dos pacientes, uma não substitui a outra. Ou seja, se a Neuropsicologia Cognitiva descreve os mecanismos da cognição e suas ligações com as estruturas cerebrais, intervindo para a reabilitação das funções deficitárias, a Psicanálise se debruça sobre o dano cognitivo na economia psíquica em geral, tendo em vista, principalmente: (a) as lesões cerebrais e sua tradução neuropsicológica, (b) a história familiar e pessoal consciente e inconsciente atualizada no e pelo adoecimento neurológico, (c) a ressonância dos problemas cognitivos e perceptivos sobre a vivência do paciente e sobre sua economia psíquica e (d) os efeitos da violência da doença. 
Ao pensar a respeito dessas interconexões entre mecanismos cognitivos, postulados pela Neurociência Cognitiva, e mecanismos de defesa inconscientes, postulados pela Psicanálise, pensamos que essas questões merecem ser desdobradas internamente ao campo psicanalítico e, também, em um confronto com as Neurociências, por meio de um trabalho de pesquisa interdisciplinar que permita entender melhor as relações entre os mecanismos cerebrais, os processos cognitivos e a emergência do inconsciente (Winograd, 2004).

Deve-se notar um aspecto importante que elucida a ideia da manutenção dos limites epistemológicos presente no grupo da interlocução, que se refere à noção de que a pesquisa em Psicanálise tem seu principal ponto de apoio na clínica, uma clínica de investigação, um espaço no qual tratamento, cura e pesquisa ocorrem simultaneamente. Além disso, é preciso atentar para a particularidade do objeto de estudo introduzido pela Psicanálise: o inconsciente. Não se trata de torná-lo apreensível pelas técnicas e métodos de investigação de outras áreas do saber, pois o inconsciente opera como um corte epistemológico ou uma ruptura paradigmática com as outras ciências, ou seja, dá início a um movimento fundador de uma nova ciência. Ao invés de impedir uma produção científica psicanalítica, como supõem os hibridadores, o que esse novo objeto revela é que se faz necessário outro entendimento da pesquisa e do conhecimento igualmente legítimo em termos de cientificidade. Neste sentido, a Psicanálise é uma ciência exatamente por apresentar um objeto de estudo definido e ter uma técnica de pesquisa que origina uma teoria coerente e sólida. A ideia central do grupo da interlocução refere-se à noção de que é imprescindível que se estabeleça uma relação de respeito mútuo entre os profissionais de cada campo a partir do entendimento de que não pode haver uma hierarquização dos modelos em jogo (Winograd, 2004, 2005).

\section{CONSIDERAÇÕES FINAIS}

Embora o diálogo entre Psicanálise e Neurociências possa enriquecer o conhecimento sobre o psiquismo humano em seus diversos aspectos, ele só se torna verdadeiramente fértil se cada disciplina mantiver o entendimento dos limites e das limitações de seu campo de ação e de reflexão - ou seja, se o recorte metodológico necessário não deslizar para uma redução explicativa e ontológica. Importa lembrar, como nos mostra o sociólogo Alain Ehrenberg ${ }^{5}$, que parte dos estudos do cérebro e a nova biologia da mente deixaram de lado os limites do neurológico e do neuroquímico para se transformarem explicitamente em ciências da vida social e da cultura (Ehrenberg, 2004). Diferentes dimensões humanas - que abrangem decisões econômicas, julgamentos morais e políticos, crenças religiosas, preferências sexuais, emoções, amor e motivações inconscientes - parecem encontrar sua chave de elucidação no vocabulário biológico. Tal vocabulário transforma-se em vocabulário final, e para ele todos os demais devem ser vertidos. Termos como Neuroteologia, Neuroeducação, Neurofilosofia, Neuroeconomia, Neuroética e Neuropolítica entram rapidamente na linguagem cotidiana, testemunhando a força do paradigma biológico na descrição e na elucidação da dinâmica da vida em sociedade (Bezerra Jr., 2006). Não obstante, Ehrenberg faz uma importante ressalva ao alertar que pensar que o homem é neuronal, como defende Changeux (1993), ou que se pode explicar o social a partir do cérebro, segundo postula Edelman (1992), seriam teses eminentemente filosóficas, mais do que hipóteses científicas.

Neste quadro, como afirma Ehrenberg (2004), o impacto das Neurociências se dá em diferentes planos que se articulam: no plano teórico, o fortalecimento de concepções fisicalistas de intenso colorido reducionista, que fazem do cérebro a base explicativa da experiência subjetiva; no plano clínico, a aproximação da Psiquiatria e da Psicopatologia ao campo da Neurologia, com o surgimento de uma perspectiva na qual as duas de fundiriam numa só disciplina; e, no plano social, a emergência dessa nova figura antropológica, o sujeito cerebral - ou seja, a crescente percepção do cérebro como detentor de propriedades e funções antes atribuídas à pessoa, ao indivíduo ou ao sujeito. Mas a ênfase neste órgão para se compreender a subjetividade parece, em grande parte, estar sendo alimentada pelo extraordinário poder de persuasão e fascínio das imagens coloridas e em movimento do funcionamento cerebral (Dumit, 2004; Ortega, 2006).

Podemos dizer, como defende Bezerra Jr. (2006), que o impacto da Biologia e das biotecnologias por meio das Neurociências, embora afete de várias maneiras o campo psicanalítico, não chega a abalar suas bases teóricas e seus dispositivos clínicos. Em verdade, ele precipitou um reordenamento no campo

Alain Ehrenberg é diretor do Cesames (Centre do recherche psychotropes, Santé mentale, Société), Université Paris Descartes (UPD): www.cesames.org. 
que tem fertilizado embates teóricos e discussões clínicas que acabaram por enriquecê-lo. Nesse contexto, pensamos ser a interdisciplinaridade fértil, na medida em que os mecanismos cerebrais, os processos cognitivos e a emergência do inconsciente estão intrinsecamente interligados, tornando-se relevante investigar as vicissitudes dessas interconexões. Porém, dialogar não implica fundir-se ou hibridar-se. Tampouco o isolamento beneficiaria o maior interessado - o paciente - já que impediria o efeito da multidisciplinaridade. Assim, parece-nos que a interlocução conduziria a uma maior compreensão do ser humano em suas diferentes dimensões - a biológica, a psíquica e a social.

\section{REFERÊNCIAS}

Alberti, S. (2003). Primeiras questões sobre psicanálise e neurociências. Trabalho apresentado em Estados Gerais da psicanálise (Segundo Encontro Mundial), Rio de Janeiro.

Andrieu, B. (2000). Le cerveau: essai sur le corps pensant. Paris: Hatier.

Bezerra Jr., B. (2006). O impacto das biotecnologias: um ponto de vista. Ide: psicanálise e cultura, 29(43), 50-56.

Changeux, J. P. (1993). L homme neuronal. Paris: Fayard.

Dumit, J. (2004). Picturing personhood: brain scans and biomedical identity. Princeton, NJ: Princeton University Press.

Edelman, G. M. (1992). Biologie de la conscience. Paris: O. Jacob.

Ehrenberg, A. (2004). Le sujet cérébral. Esprit, 309, 130-155.

Elia, L. (1999). Uma ciência sem coração. Revista Agora: estudos em teoria psicanalítica, 2(1), 41-53.

Freud, S. (1969). Esboço de Psicanálise. (J. Salomão, Trad.), Edição Standard Brasileira das Obras Psicológicas Completas (Vol. 23, pp. 169-237). Rio de Janeiro: Imago. (Originalmente publicado em 1940 [1938]).

Freud, S. (1976a). Além do princípio do prazer. (J. Salomão, Trad.), Edição Standard Brasileira das Obras Psicológicas Completas (Vol. 23, pp. 17-85). Rio de Janeiro: Imago. (Originalmente publicado em 1920).

Freud, S. (1976b). A questão da análise leiga. (J. Salomão, Trad.), Edição Standard Brasileira das Obras Psicológicas Completas (Vol. 20, pp. 209-283). Rio de Janeiro: Imago. (Originalmente publicado em 1926).

Freud, S. (1976c). Pós-escrito. (J. Salomão, Trad.), Edição Standard Brasileira das Obras Psicológicas Completas (Vol. 20, pp. 209283). Rio de Janeiro: Imago. (Originalmente publicado em 1927).

Freud, S. (2004). Pulsões e destinos da pulsão. (L. A. Hanns, Trad.), Obras psicológicas de Sigmund Freud (1911-1915). Volume I: Escritos sobre a psicologia do inconsciente (Vol. 1, pp. 145-173). Rio de Janeiro: Imago. (Originalmente publicado em 1915).
Imbriano, A. (2008). El Drang más allá del modelo neorofisiológico. Psicoanálisis e el Hospital, 17(33), p. 181-185.

Kandel, E. R. (1999). Biology and the future of psychoanalysis: a new intellectual framework for psychiatry revisited. The American Journal of Psychiatry, 156, 505-524.

Kaplan-Solms, K. \& Solms, M. (2004). O que é a neuro-psicanálise: a real e difícil articulação entre a neurociência e a psicanálise. São Paulo: Terceira Margem.

Kaplan-Solms, K. \& Solms, M. (2005). Estudos clínicos em neuropsicanálise. São Paulo: Lemos Editorial.

Kernberg, O. (2006). The pressing need to increase research in and on psychoanalysis. International Journal of Psychoanalysis, 87(4) 919-926.

Lacan, J. (1979). Desmontagem da pulsão. (M. D. Magno, Trad.). $O$ Seminário, livro 11: Os quatro conceitos fundamentais da psicanálise. (pp. 153-164). Rio de Janeiro: Zahar. (Originalmente publicado em 1964).

Lacan, J. (1981). Séminaire, 1961-1962. 1, L'identification. Paris : Éditions du Piranha.

Lacan, J. (1993). Subversión del sujeto y la dialéctica del inconsciente freudiano. (T. Segovia, Trad.), In Escritos II (17a. ed., pp. 773807). México: Siglo Veintiuno ed. (Originalmente publicado em 1960).

Miller, J.-A. (1987). Percurso de Lacan: uma introdução. Rio de Janeiro: J. Zahar.

Olds, D. \& Cooper, A. M. (1997). Dialogue with other sciences: opportunities for mutual gain. International Journal of Psychoanalysis, 78(2), 219-225.

Ortega, F. (2006). O corpo transparente: visualização médica e cultura popular no século XX. História, ciências, saúde - Maguinhos, 13 (Supl.), 89-107.

Solms, M. (2007). Sigmund Freud hoy. Revista Psicoanálisis, 5, 115119.

Soussumi, Y. (2003). Uma experiência prática de psicanálise fundamentada pela neuro-psicanálise. Revista Brasileira de Psicanálise, 37(2/3), 573-596.

Winnicott, D. W. (1988). Distorção do ego em termos de falso e verdadeiro self. (I. C. S. Ortiz, Trad.), O ambiente e os processos de maturação: estudos sobre a teoria do desenvolvimento emocional (2a. ed., pp. 128-139). Porto Alegre: Artes Médicas. (Originalmente publicado em 1960).

Winograd, M. (2004). Matéria pensante - a fertilidade do encontro entre psicanálise e neurociência. Arquivos Brasileiros de Psicologia, 56(1/2), 24-38.

Winograd, M. (2005). Psicanálise e Neurociência: condições para o debate. Anais do CONPSI. Congresso Norte-Nordeste de Psicologia, 4, Salvador, Ba.
Recebido em 09/07/2009 Aceito em 31/08/2010
Endereço para correspondência:

Marcia Moraes Davidovich. Rua Mário Pederneiras 10/117, Humaitá, CEP: 22261-020, Rio de Janeiro-RJ, Brasil. E-mail: madovic@attglobal.net. 